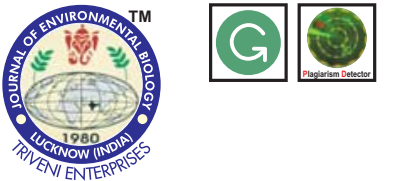

DOI : http://doi.org/10.22438/jeb/38/4/MS-169

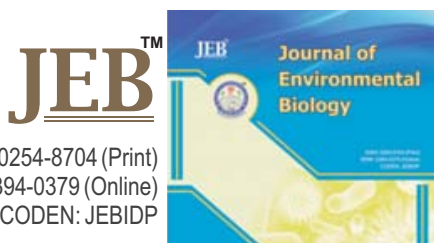

\title{
Neuroprotective effects of curcumin on sodium fluoride induced behavioural and enzymatic changes in brain and muscles of rat
}

Authors Info

M. Nageshwar, K. Sudhakar, N.C.S. Reddy and K.P. Reddy*

Department of Zoology, Osmania University, Hyderabad-500 007, India

*Corresponding Author Email : pratapkreddyou@osmania.ac.in

Key words

Behavioural changes,

Curcumin,

Membrane bound enzymes,

Sodium fluoride

Publication Info

Paper received : 24.09 .2015

Revised received : 16.07.2016

Re-revised received : 22.11.2016

Accepted : 30.11 .2016

\section{Abstract}

Aim: The study reports protective role of curcumin, a polyphenolic compound, against sodium fluoride (NaF) induced oxidative stress, altered cognitive, motor abilities and $\mathrm{AChE}, \mathrm{Na}^{+}-\mathrm{K}^{+} \mathrm{ATP}$ ase activities in rat.

Methodology: Rats were divided into three groups. The first group received normal tap water that served as control. The second group was treated with sodium fluoride $\left(20 \mathrm{mg} \mathrm{kg}^{-1} \mathrm{~b}\right.$. wt.). The third group was treated with sodium fluoride $\left(20 \mathrm{mg} \mathrm{kg}^{-1}\right.$ b.wt.)+Curcumin $\left(20 \mathrm{mg} \mathrm{kg}^{-1}\right.$ b.wt.) through drinking water by gavage for 30 days.

Results: The body weight (-22.55\%), somatic index (-15\%, -26.72\%), membrane bound enzymes $\mathrm{Na}^{+}-\mathrm{K}^{+}$ ATPase $(-34.72 \%,-35.97 \%)$ and AChE activities $(-44.70 \%,-38.83 \%)$ were significantly $(p<0.05)$ decreased and oxidative stress marker lipid peroxidation level $(67.96 \%, 72.46 \%)$ was increased in sodium fluoride intoxicated group as compared to control group. The motor coordination $(-43.18 \%,-39.90 \%)$, locomotor ($41.45 \%)$ and nociceptive pain $(-14.78 \%,-15.98 \%)$ abilities were diminished in sodium fluoride treated group as compared to control group, whereas body weight, somatic index, membrane bound enzymes $\mathrm{Na}^{+}-$ $\mathrm{K}^{+}$ATPase, AChE activities, lipid peroxidation levels and motor coordination, locomotor and nociceptive pain abilities were significantly $(p<0.05)$ reversed in curcumin treated along with sodium fluoride group compared to $\mathrm{NaF}$ treated group.

Interpretation: The results of the present study showed that c u r c u m in ameliorated the oxidative stress, membrane bound enzyme activities in muscle and brain, as well as motor, pain and cognitive abilities of rat induced by $\mathrm{NaF}$ exposure.
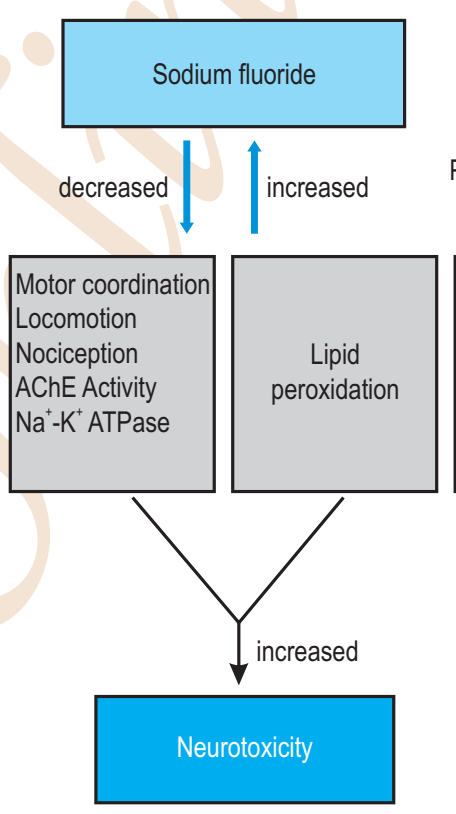

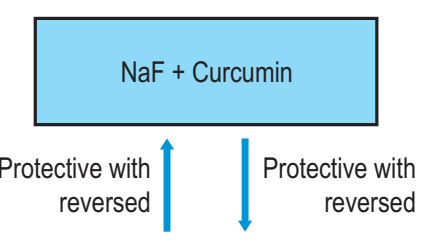

Motor coordination Locomotion Nociception AChE Activity $\mathrm{Na}^{+}-\mathrm{K}^{+}$ATPase
Lipid peroxidation
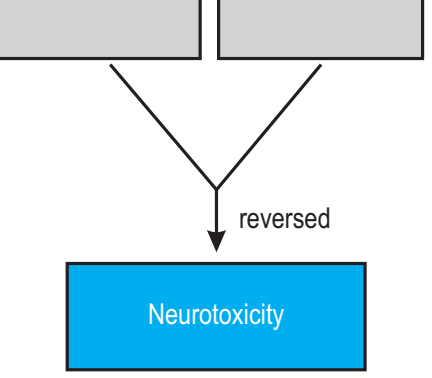


\section{Introduction}

Fluoride is an essential element required for prevention of skeletal and dental caries, whereas excessive accumulation of fluoride from either natural or anthropogenic ways could result in fluorosis. Intoxication of fluoride may occur through drinking water, food, and industrial sources and also from fluoride abuse in dental care substances (Radha et al., 2011; Nan et al., 2016). In chronic fluorosis, neurological disorders have been observed in humans and animals (Xiang et al., 2003). Fluorosis can lead to serious impairments in the central nervous system especially injuring the nerve cells. It was reported that correlations between fluorosis (Mukul and Arora, 2007; Daisy and Khan, 2008) and some trace elements, and oxidative stress leads to neurological disorders (Nabavi et al., 2011; Philippe et al., 2014). Pathological effects of fluoride intake have been reported for various organs including brain, kidney, liver and thyroid of human living in areas with endemic fluorosis in several developing countries, including China and India (Varner et al., 1998; Nabavi et al., 2011). Excessive intake of fluoride may cross the blood-brain barrier and accumulate in the brain, causing dysfunction of the central nervous system (Mullenix et al., 1995; Nan et al., 2016). Fluoride neurotoxicity is manifested through several behavioural and neurochemical alterations, which display diversity depending on the animal species, the administration route and the chemical form of sodium fluoride administered (Chirumari and Reddy, 2007). It has been demonstrated that sodium fluoride (NaF) promotes oxidative stress in the mice brain, and damage of lipids, membrane-associated proteins, $\mathrm{Na}^{+}-\mathrm{K}^{+}$ATPase and protein kinase C (Vani and Reddy, 2000). Fluoride has been shown to alter lipid peroxidation and activity of certain enzymes and molecules such as $\mathrm{Na}^{+}-\mathrm{K}^{+}$ATPase (Karnati et al., 2009). Lipid peroxidation products can trigger the excitotoxic process. Since fluoride can inhibit these enzymes, even at low concentrations, there is an increased chance of excitotoxicity which plays a significant role in the neurodegenerative process (Blaylock et al., 2004). $\mathrm{Na}^{+}-\mathrm{K}^{+}$ATPase maintains ion balance across the membrane. Due to inhibition of $\mathrm{Na}^{+}-\mathrm{K}^{+}$ATPase by fluoride exposure leads to disturbance in ion homeostasis across the nerve cell, thus resulting in reduced cellular polarization (depolarizing effect) (Malek et al., 2005). Curcumin can protect against free radical by scavenging, exert antioxidant ability and prevent $\mathrm{Na}^{+}-\mathrm{K}^{+} \mathrm{ATP}$ ase damage from fluoride exposure, and thus helpful in treatment of fluoride generated neurodegeneration (Kiran Kumar et al., 2015).

Curcumin is an ancient Indian herb, and has powerful antioxidant and anti-inflammatory properties (Khalid et al., 2015; Stephanie et al., 2015). Recent studies on the use of natural and complementary medicines in western medicine have drawn the attention of the scientific community to this natural product. Curcumin has anti-inflammatory, antioxidant, chemopreventive and chemotherapeutic activities (Nabavi et al., 2011). Curcumin is more potent free-radical scavenger, protects the soft tissues from lipid peroxidation, and scavenges nitric oxide based radicals and also curcumin inhibits amyloid aggregation in in vitro studies. Numerous analogues of curcumin have been developed for therapeutic purposes. It is well established that large quantities of curcumin can be consumed without toxicity (Suresh et al., 2011). The anti-inflammatory effects of curcumin involves different mechanisms of action i.e., it can regulate the activation of transcription factors such as activating protein-1 and nuclear factor kappa B (NF-kB) in monocytes or macrophages, and it can block the induction of cyclooxygenase-2. It is reported that the curcumin has shown to inhibit the release of the pro-inflammatory cytokines IL-1, IL-6, and tumor necrosis factor (TNF) by down regulating intercellular signalling proteins such as protein kinase C (Esther et al., 2015). Collectively, the present study reports the neuroprotective role of curcumin against sodium fluoride induced neurotoxicity.

\section{Materials and Methods}

Animals : Healthy adult albino Wistar rats (Rattus norvegicus) were obtained from the National Centre for Laboratory Animal Sciences, National Institution of Nutrition, Hyderabad, India. The rats were maintained under suitable laboratory conditions with 12:12 hour light: dark cycle. The animals were fed with a standard pellet diet and given distilled water ad libitum. The animals were allowed to acclimatize to the laboratory conditions for a week before experimentation. The rats (weighed 200-230 gms) were randomly divided into three groups of five each. Group I animals served as control and given normal tap water, Group II animals were administered with sodium fluoride $\left(20 \mathrm{mg} \mathrm{kg}^{-1} \mathrm{~b}\right.$.wt.) through drinking water and Group III animals received sodium fluoride (20 $\mathrm{mg} \mathrm{kg}^{-1}$ b.wt.) and simultaneously curcumin ( $20 \mathrm{mg} \mathrm{kg}^{-1}$ b.wt.) by gavage. The treatment was continued for a period of 30 days. The behavioural studies (Randall-Selitto test and Rota Rod test) were conducted on 15 and 30 days period. The brain and muscle were dissected and stored at $-20^{\circ} \mathrm{C}$ for biochemical estimations.

Body weight and organo-somatic index: The body weight of each animal was noted before treatment and also on day 30 . The weight of muscle and whole brain of respective groups of animals were recorded and organo-somatic index was calculated.

\section{Behavioural study}

Randall Selitto test : The nociceptive withdrawal threshold was assessed by using the Randall-Selitto test (Randall and Selitto, 1957). The test was used to detect pain in experimental, as well as control group of animals $(n=6)$. The test was performed on 15 and 30 days period after intoxication. Before test, each animal received 5 min of handling to get used to manipulation; then it was placed into a soft cotton cloth and carefully immobilized with the same hand used to hold the tested paw. The test consisted of the application of an increasing mechanical force, in which the tip of 
the device was applied onto the dorsal surfaces of both fore and hind paws until a withdrawal response resulted. The point of application was marked with ink in order to maintain the location over repeated trials. The maximum force applied was limited to $250 \mathrm{~g}$ to avoid skin damage. The Randall-Selitto test was performed once on each individual and, after an entire round on all individuals, it was repeated again on the same day for five times. The obtained results were expressed in pounds.

Rota rod test : Rota Rod is a tool to investigate the motor coordination in diseased conditions in laboratory animals like mice and rat. The test was performed according to the Boix et al. (2010). The time of the instrument (Model-Rota Rod 4 compartments Dolphin ${ }^{\mathrm{TM}}$ instruments) was adjusted to 0 Seconds and the rotate speed to $20 \mathrm{rpm}$ prior to the experiment. Animals were placed on the rotating rod and pressed the start button. Animals were themself co-ordinated the body on rotating rod (innate antagonistic reflex activity), but when they were unable to cope up, fallen on the base of instrument consisting a sensor, which stops the stop watch. The time was noted and expressed in seconds.

Open field test : The open field test is designed to measure behavioural activities such as locomotor activity, hyperactivity and exploratory behaviours (emotional reactivity/ anxiety). The test was carried out according to the method of Netto et al. (1986).In this experiment, the open field behaviour of rats was assayed in a wooden box measuring $90 \times 90 \times 30 \mathrm{~cm}$. The floor of the area was divided in to 36 equal squares. The animals were allowed into open field for $5 \mathrm{~min}$. Each rat was placed in a corner of the field. The number of squares crossed with all paws (crossing), the standings on the hind legs (rearing), standing on hind legs and placing forelimbs on the wall of arena (wall rearing), placing the nose against wall or floor (sniffing), wiping, liking, combining or scorching of any part of the body (grooming) were counted as the sum of all open-field tasks give total behaviour and noted the rating values and analyzed by using one way-ANOVA and expressed as time in minutes (counts/5mins).

Lipid Peroxidation (MDA) estimation : Lipid peroxidation in brain tissue was measured by employing modified method of (Bhuyan et al., 1981). $1 \mathrm{ml}$ of $10 \%$ homogenate was added to $1 \mathrm{ml}$ of $20 \%$ TCA and heated at $70{ }^{\circ} \mathrm{C}$ for $10 \mathrm{~min}$ and cooled at room temperature and centrifuged at $3000 \mathrm{rpm}$ for $10 \mathrm{~min} .400 \mu \mathrm{L}$ of supernatant was mixed with $200 \mu \mathrm{L}$ of $0.5 \%$ TBA reagent in a testtube covered with a glass marble and heated in a boiling water bath for $10 \mathrm{~min}$ after the tube cooled to room temperature. The absorbance of the pink coloured trimethine condensation product was measured at $533 \mathrm{~nm}$ using a spectrophotometer. The results were expressed as MDA (nmol g ${ }^{-1}$ tissue).

$\mathrm{Na}^{+}-\mathrm{K}^{+}$ATPase activity : The $\mathrm{Na}^{+}-\mathrm{K}^{+}$ATPase activity was assayed according to Kaplay (1978) and the inorganic phosphate was estimated by the method of Taussky and Shorr (1953). The homogenates of muscle and brain were prepared in $0.25 \mathrm{M}$ icecold sucrose solution and centrifuged in a refrigerated centrifuge at 20,000 rpm for $30 \mathrm{~min}$ and the supernatant was used for the assay. The difference in the activity of the enzyme in the absence and presence of ouabain was taken as $\mathrm{Na}^{+}-\mathrm{K}^{+}$ATPase activity respectively. The enzyme activity was expressed as nanomoles of Pi liberated $\mathrm{mg}^{-1}$ protein $\mathrm{min}^{-1}$.

Acetylcholine esterase activity: Acetylcholine esterase activity was estimated by the method of Ellman et al. (1961). The homogenates of muscle and brain were prepared in a buffer containing $1 \mathrm{mM}$ EDTA, $200 \mathrm{mM} \mathrm{NaCl}$ and $0.4 \%$ Triton $X 100$ in $0.1 \mathrm{M}$ potassium phosphate buffer $(\mathrm{pH} 8)$ and centrifuged at $4^{\circ} \mathrm{C}$ at 20,000 rpm for $30 \mathrm{~min}$ and the supernatant was used for enzyme assay. The activity was determined by using molar extinction coefficient for 5, 5'-dithio-bis-2-nitrobenzoic acid (DTNB) as $1.36 \times 10^{4}$ per mole. AChE activity was expressed as nanomoles of acetylcholine hydrolysed $\mathrm{mg}^{-1}$ protein $\mathrm{min}^{-1}$.

Statistical analysis : Statistical analysis was performed using SPSS version 20 software. Mean \pm SEM (standard error) was calculated and multiple comparison test, one way ANOVA were performed for statistical significance $(p<0.05)$.

\section{Results and Discussion}

The present study evidenced that sodium fluoride consumption showed alteration in motor, cognitive, nociceptive behaviour and induced significant changes in the oxidative stress; membrane bound enzymes activities in rat. The administration of curcumin simultaneously with sodium fluoride reduced the oxidative stress, increased enzymes activities and improved behavioural abilities in rats. Vani and Reddy (2000) reported decreased somatic index of muscle and brain in fluoride treated mice. It is evidenced in the present study that the body weight and organo somatic index (OSI) (Fig. 1a, b) of muscle ($26.72 \%)$ and brain $(-15 \%)$ of fluoride exposed rats were decreased significantly $\left({ }^{a} p<0.05\right)$ as compared to control, whereas the $\mathrm{NaF}+\mathrm{Curcumin}$ treated group showed increased OSI of brain $(-5.71 \%)$ and muscle $(-10.34 \%)$ as compared to fluoride administered rats and results were nearer to control rats $\left({ }^{b} p<0.05\right)$. The body, brain and muscle weights were proportionately reduced in fluoride treated rats as compared to control group individuals and improved in the above weights in curcumin received rats.

The Randall Selitto pain test detects a noxious stimulus such as feeling of pain, caused by stimulation of nociceptors. This test used for studying pain conditions affecting the limbs by applying mechanical force on dorsal surface of hind paw (Esther et al., 2015). The anti-nociceptive effects seem to result from their inhibitory effect on reactive oxygen species such as NO, PKC, cytokine production and inhibition of NF-KB which play a role in increasing pain in fluorosis. The sodium fluoride induced pain 


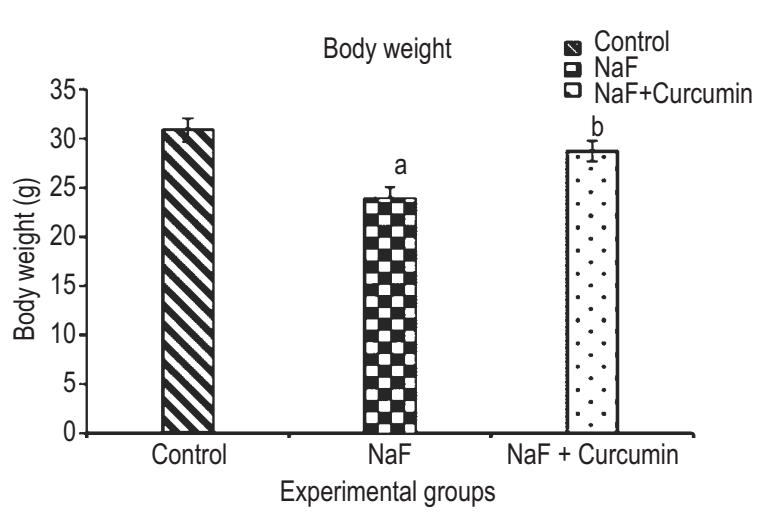

Fig. 1 (a) : Effect of curcumin on body weight of fluoride-exposed rats after 30 days. Values are mean of five replicates \pm SE; ${ }^{a} p<0.05$ compared with control, ${ }^{b} p<0.05$ compared with the fluoride-alone treated group. Body weight was expressed in grams

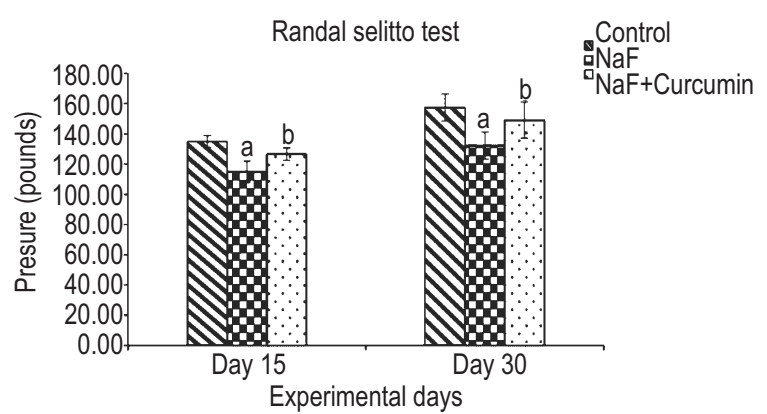

Fig. 2(a) : Effect of curcumin on Randal selitto pressure (pounds) in fluoride-exposed rats after 30 days. The response is expressed in terms of pressure (Pounds). Values are mean of five replicates $\pm S E$; ${ }^{a} p<0.05$ compared with control, ${ }^{b} p<0.05$ compared with the fluoride-alone treated group

combination with curcumin resulted in significant increase in the pain threshold in the paw pressure tests indicating the effectiveness of combination therapy in ameliorating pain. The fluoride exposed rats showed increased $(-14.78 \%$ and $-15.98 \%$ on day 15 and on day 30 respectively) threshold stimulus for pain significantly ( $\left.{ }^{a} p<0.05\right)$ as compared with control group. Whereas, curcumin treated group showed reduced $(-6.24 \%$ and $-5.29 \%$ on day 15 and on day 30 respectively) threshold intensity to generate pain sensitivity as compared to fluoride treated group $\left({ }^{b} p<0.05\right)$ (Fig. 2a). NaF inhibited exploratory motor activity and the effect was accompanied by a decreased activity of AChE in the brain (Vani and Reddy, 2000). Therefore, a derangement of central cholinergic activity may account for a deficit in motivated locomotor behaviour in NaF-treated animals. A suppression of eating and drinking processes caused by a defect in motivated locomotor behaviour may account for a decreased food and water intake (Kahan et al., 2014). Atrophic gastritis produced by chronic oral treatment of $\mathrm{NaF}$ (Das et al., 2006) may also contribute to decreased food and water intake in these animals. The fluoride

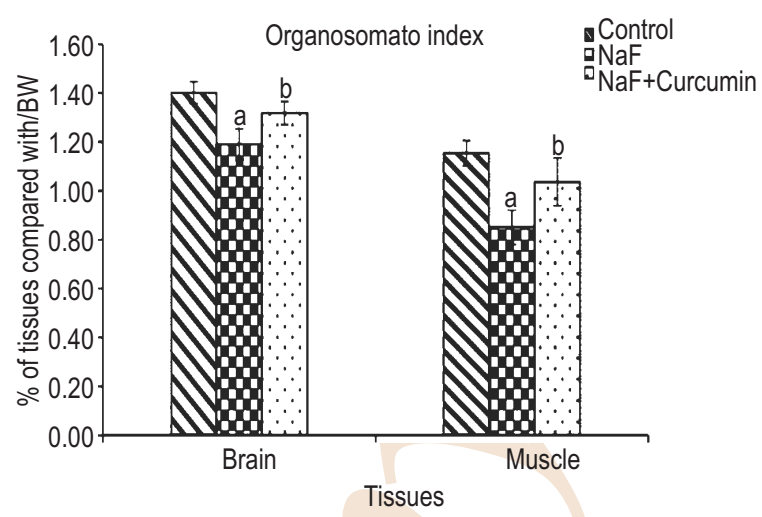

Fig. 1 (b) : Effect of curcumin on Organo somatic index after 30 days of muscle and brain of fluoride-exposed rats. Values are mean of five replicates $\pm \mathrm{SE} ;{ }^{a} p<0.05$ compared with control, ${ }^{b} p<0.05$ compared with the fluoride-alone treated group

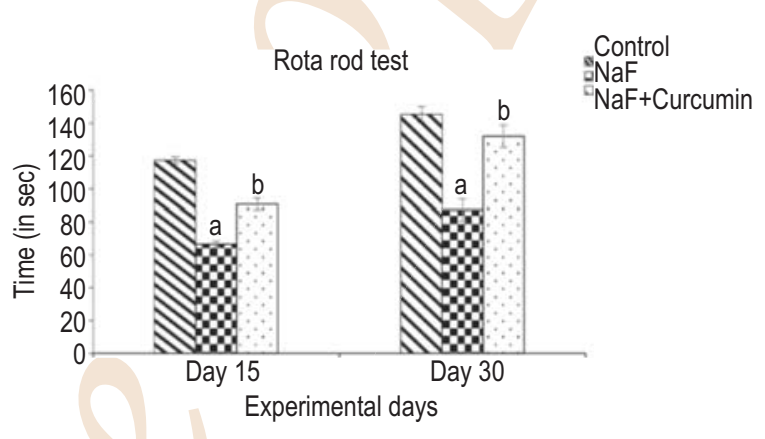

Fig. 2 (b) : Effect of curcumin on Rotarod endurance in fluoride-exposed rats after 30 days. Values are mean of five replicates $\pm S E ;{ }^{a} p<0.05$ compared with control, ${ }^{b} p<0.05$ compared with the fluoride-alone treated group

intoxicated animals were unable to regulate their body coordinately and fell from the rota rod earlier than control group, whereas curcumin treated group were retained for longer time and nearer to control. The rota rod test revealed significant decrease $(-43.18 \%$ on day $15,-39.90 \%$ on day 30$)$ in endurance time of fluoride-exposed animals when compared with control $\left({ }^{a} p<0.05\right)$. Curcumin treated group improved in performance on rota rod and showed increased $(-22.71 \%$ on day $15,-9.22 \%$ on day 30 ) endurance time when compared with the fluoride treated group ( $\left.{ }^{b} p<0.05\right)$ (Fig. 2b). Various parameters of motor activity such as latency, grooming, rearing, crossing, sniffing and wall rearing were used as the main indices of emotional reactivity in the open field test. The open-field test showed increased anxiety behaviour induced by sodium fluoride intake by rats. The reduced dopamine level may lead to decrease the open field rearing, scratching behaviours in rat, which clearly show an association of dopamine with complex stereo type behaviours of fluoride intoxication. Fig. 3 showed anxiety, as well as locomotor behaviours such as crossing, rearing, wall rearing, sniffing and 


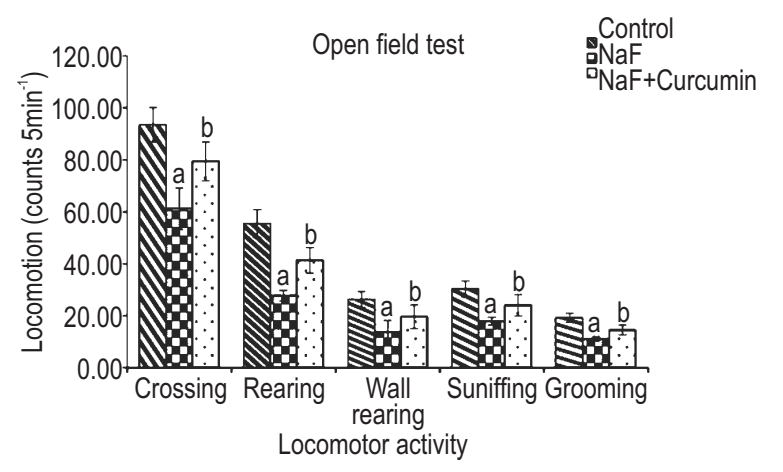

Fig. 3 : Effect of curcumin on crossing, rearing, wall rearing, sniffing and grooming in the open field in fluoride-exposed rats after 30 days. Values are mean of five replicates $\pm \mathrm{SE} ;{ }^{a} p<0.05$ compared with control, ${ }^{b} p<0.05$ compared with the fluoride-alone treated group

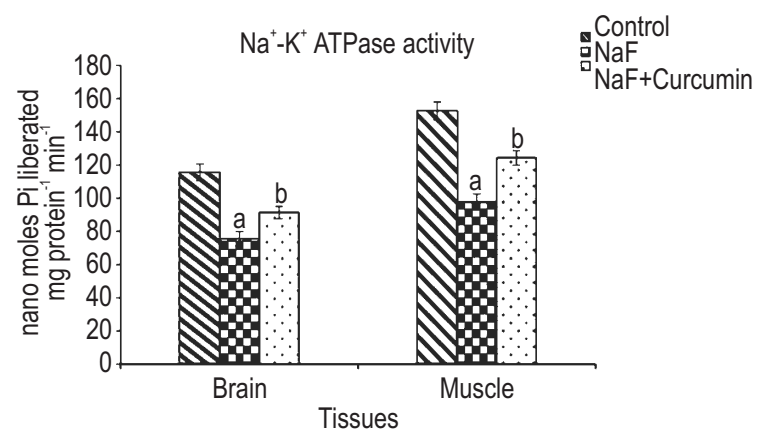

Fig. 4(b) : Effect of curcumin on $\mathrm{Na}^{+}-\mathrm{K}^{+}$ATPase activity in brain and muscle of fluoride-exposed rats after 30 days. The enzyme activity is expressed as nanomoles of Pi liberated $\mathrm{mg}^{-1}$ protein $\mathrm{min}^{-1}$. Values are mean of five replicates $\pm \mathrm{SE} ;{ }^{a} p<0.05$ compared with control, ${ }^{b} p<0.05$ compared with the fluoride-alone treated group

grooming were decreased $(-41.45 \%)$ in fluoride exposed rats when compared with the control $\left({ }^{a} p<0.05\right)$, whereas curcumin treated group showed improvement of locomotor activities and reduced $(-20.36 \%)$ anxiety behaviour as compared to fluoride treated group $\left({ }^{\mathrm{b}} \mathrm{P}<0.05\right)$.

Oxidative stress can cause damage to membrane lipids, proteins and anti-oxidative enzyme defense system, thus resulting in oxidative modifications in cerebral tissue. Sodium fluoride induces oxidative stress and apoptosis in PC 12 cell (Jie et al., 2015). MDA increase is an important indicator of lipid peroxidation, which is a well-known paradigm of damage to membranes under conditions of oxidative stress. Furthermore, MDA plasma levels have often been used as an oxidative biomarkers for D-galactose-induced aging models (Suresh et al., 2011; Nabavi et al., 2011). Curcumin is much stronger than vitamin $E$ as a free-radical scavenger, protects the brain from lipid peroxidation, and scavenges nitric oxide (NO)-based radicals. In in vitro studies have reported that curcumin inhibits amyloid

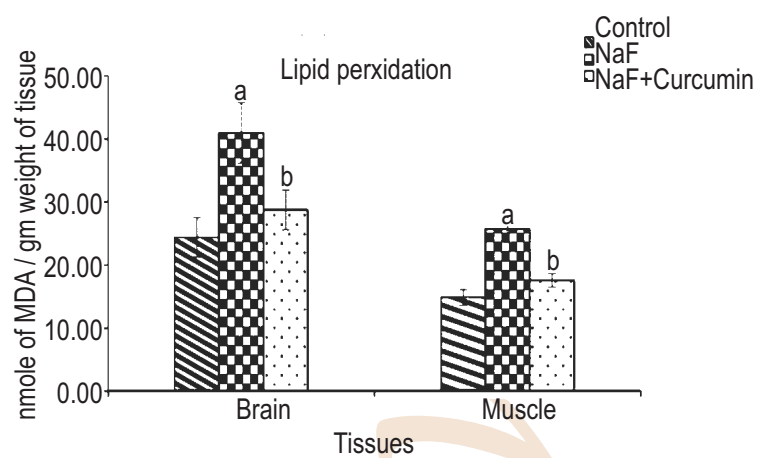

Fig. 4(a) : Effect of curcumin on lipid peroxidation levels ( $\mathrm{nmol}$ of $\mathrm{MDAg}^{-1}$ tissue) in brain and muscle of fluoride-exposed rats after 30 days. Values are mean of five replicates \pm SE; ${ }^{a} p<0.05$ compared with control, ${ }^{b} p<0.05$ compared with the fluoride-alone treated group

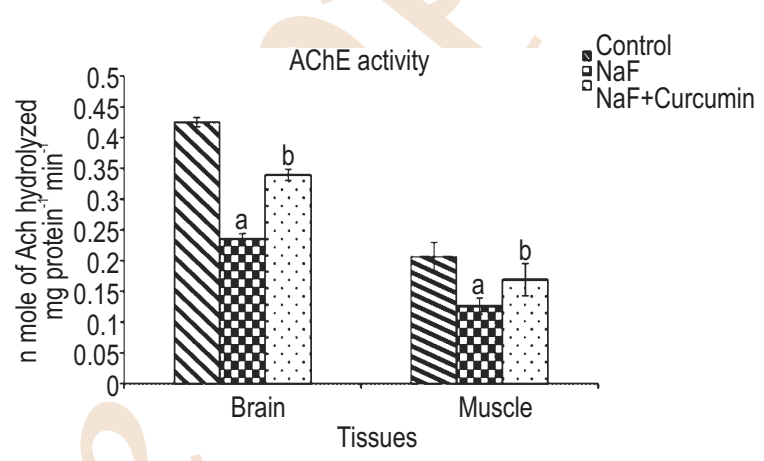

Fig. 4(c) : Effect of curcumin on Acetylcholine esterase activity in brain and muscle of fluoride-exposed rats after 30 days. AChE activity is presented as nanomoles of acetylcholine hydrolysed $\mathrm{mg}^{-1}$ protein $\mathrm{min}^{-1}$ Values are mean of five replicates $\pm S E ;{ }^{a} p<0.05$ compared with control, ${ }^{b} p<0.05$ compared with the fluoride-alone treated group

aggregation (Elmegeed et al., 2015). Lipid peroxidation level was increased $(-67.96 \%$ in brain, $-72.46 \%$ in muscle) in fluoride treated group $\left({ }^{a} p<0.05\right)$ as compared with control, whereas curcumin treated group reduced $(-17.96 \%$ in brain, $-18.06 \%$ in muscle) the level of lipid peroxidation $\left({ }^{b} p<0.05\right)$ as compared to fluoride treated group (Fig. 4a). Thus, the present report evidenced that the curcumin had antioxidant properties, and protects muscle and brain from sodium fluoride induced oxidative stress.

Membrane bound enzyme $\mathrm{Na}^{+}-\mathrm{K}^{+}$ATPase plays an important role in active transport of $\mathrm{Na}^{+}$and $\mathrm{K}^{+}$ions across the plasma membrane. The enzyme is present in high concentration in brain and muscle. Vani and Reddy (2000) reported inhibition of the enzyme due to fluoride exposure. The $\mathrm{Na}^{+}-\mathrm{K}^{+}$ATPase and $\mathrm{Ca}^{2+}$ ATPase activities were inhibited by a single oral administration of $\mathrm{NaF}$ in mice (Vani and Reddy, 2000). Significant inhibition of $\mathrm{Na}^{+}-\mathrm{K}^{+}$ATPase by $\mathrm{NaF}$ might be another causative factor for the change in neuronal metabolism leading to 
neuromuscular dysfunction in mice during $\mathrm{NaF}$ exposure along with inhibition of AChE (Rayavara et al., 2006). The fluorideinduced effects could also be due to internal injury to the cell membrane, which would affect the activity of membrane bound enzymes like $\mathrm{Na}^{+}-\mathrm{K}^{+}$ATPase by disturbing membrane fluidity, membrane integrity and altering its permeability which may result in disturbance in the concentration of $\mathrm{Mg}^{2+}$. Acetylcholine, a neurotransmitter plays a key role in memory formation by enhancing long-term potentiation in the hippocampus. Physiological effect of acetylcholine was terminated by its degradation caused by an enzyme, AChE. Impaired cholinergic transmission was evident in various neurological diseases associated with cognitive impairment. The enzymes $\mathrm{Na}^{+}-\mathrm{K}^{+}$ ATPase (-34.72\% in brain, $-35.97 \%$ in muscle) and acetylcholine esterase activities (-44.70\% in brain, $-38.83 \%$ in muscle) were decreased significantly $\left({ }^{\mathrm{P}} \mathrm{P}<0.05\right)$ in the fluoride treated group as compared to control. The AChE activity was reduced in sodium fluoride treated mice, which was in concordance with the earlier reports on mice of Vani and Reddy (2000). The activities of enzymes $\left(\mathrm{Na}^{+}-\mathrm{K}^{+}\right.$ATPase $-21.04 \%$ in brain, $-18.56 \%$ in muscle, AChE activity $-20.23 \%$ in brain, $-17.96 \%$ in muscle) were restored in curcumin treated group when compared to the fluoride treated group $\left({ }^{b} p<0.05\right)$ (Fig.4b,4c).

In conclusion, the present study demonstrated that curcumin has neuroprotective effects against sodium fluoride induced neurotoxicity in rat. Administration of curcumin ameliorated oxidative stress, enzymes activities, motor, pain and cognitive alteration induced by sodium fluoride. Hence, this study reported that curcumin is more potent neuroprotectant against $\mathrm{NaF}$ induced toxicity.

\section{Acknowledgments}

Authors acknowledge the financial support from UGC -DSA and BSR and also P.G. Students, A. Sravanthi, K. Raju, A. Laxman, V. Sravanthi, A. Mahender and Ramesh who have participated in conducting the experiments at the Department of Zoology, Osmania University, Telangana, India.

\section{References}

Bhuyan, K.C., D.K. Bhuyan and N. Johansen: Estimation of malondialdehyde. IRCSMed. Sci., 9, 126-127 (1981).

Blaylock, R.: Excitotoxicity a possible central mechanism in fluoride neurotoxicity. Fluoride, 37, 301-314(2004).

Boix, J., O. Cauli and V. Felipo: Developmental exposure to polychlorinated biphenyls 52, 138 or 180 affects differentially learning or motor coordination in adult rats. Mechanisms involved. Neuroscience, 167, 994-1003 (2010).

Chirumari, K. and K.P. Reddy: Dose dependent effects of fluoride on neurochemical milieu in hippocampus and neocortex of rat brain. Fluoride, 40, 101-110 (2007).

Daisy, S. and T.I. Khan: Fluoride contamination status of groundwater in Phulera tehsil of Jaipur district, Rajasthan. J. Environ. Biol., 29, 871-876 (2008).
Das, S., R. Maiti and D. Ghosh: Fluoride induced immunotoxicity in adult male albino rat: A correlative approach to oxidative stress. J. Immunotoxicol., 3, 1-7 (2006).

Ellman, G.L., U.D. Courtney, V.A. Junior and R.M. Featherstone: A new and rapid colorimetric determination of AChE activity. Biochem. Pharmacol., 7, 88-95 (1961).

Elmegeed, G.A., H. Hanaa, Ahmed, A. Maher, Hashash, M.M. AbdElhalim, S. Dina and El-kady: Synthesis of novel steroidal curcumin derivatives as anti-Alzheimer's disease candidates: Evidences-based on in vivo study. Steroids, 101, 78-89 (2015).

Hagl, S., A. Kocher, Ch. Schiborr, N. Kolesova, J. Frank and G.P. Eckert: Curcumin micelles improve mitochondrial function in neuronal PC12 cells and brains of NMRI mice-Impact on bioavailability. Neurochem. Int., 89, 234-242 (2015).

Jie, W., M. Cheng, Q. Liu, J. Yang, S. Wu, X. Lu, C. Jin, H. Ma and Y. Cai: Protective role of tert-butylhydroquinone against sodium fluorideinduced oxidative stress and apoptosis in PC12 cells. Cell Mol. Neurobiol., 35, 1017-1025 (2015).

Kahan, J., M. Urner, R. Moran, G. Flandin, A. Marreiros, L. Mancini, M. White, J. Thornton, T. Yousry, L. Zrinzo, M. Hariz, P. Limousin, K. Friston and T. Foltynie: Resting state functional MRI in Parkinson's disease: The impact of deep brain stimulation on effective connectivity. Brain J. Neurol.,137, 1130-1144 (2014).

Kaplay, S.S.: Erythrocyte membrane Na+ -K+ ATPase in protein caloric malnutrition. Amer. J. Clin. Nutr., 31, 579-84 (1978).

Karnati, P.R., G. Sailaja and C. Krishnaiah: Protective effects of selenium on fluoride induced alterations in certain enzymes in brain of mice. J. Environ. Biol., 30, 859-864 (2009).

Khalid, K.A., R. Syed and I.A. Khan: Computational study on the interaction of flavonoids with fat mass and obesity associated protein. J. Environ. Biol., 36, 419-424, (2015).

Kiran Kumar, N., R.R. Banala and P.R. Karnati: Curcumin protection against oxidative stress induced neural damage in developing brain of rat with fluoride exposure. I. J. Bioass., 4, 4077-4081 (2015).

Malek, S.A., J.S. Adorante and P.K. Stys: Differential effects of Na-KATPase pump inhibition, chemical anoxia, and glycolytic blockade on membrane potential of rat optic nerve. Brain Res., 10,171-179 (2005).

Mukul, B. and S. Arora: Potable groundwater quality in some villages of Haryana, India: Focus on fluoride. J. Environ. Biol., 28, 291-294 (2007).

Mullenix, P.J., P.K. Denbesten, A. Schunior and W.J. Kernan: Neurotoxicity of sodium fluoride in rats. Neurotoxicol. Teratol., 17, 169-177 (1995).

Nabavi, S.F., S.H. Eslami, A.H. Moghaddam and S.M. Nabavi: Protective effect of curcumin against fluoride induced oxidative stress in rat brain. Neurophysiol., 43, 287-291(2011).

Nan, Y., Y. Liu, S. Liu, S. Cao, F. Wang, Z. Wang and S. Xi: Fluoride: Induced neuron apoptosis and expressions of inflammatory factors by activating microglia in rat brain. Mol. Neurobiol., 53, 4449-4460 (2016)

Netto, C.A., R.D. Dias and I. Izquiedo: Differenial effect of post training naloxone, beta-endorphin, leu-enkephalin and electroconvulsive shock administration upon memory of an open-field habituation and of a water-finding task. Psycho. Neuroendocrinol., 11, 437446 (1986).

Parada, E., I. Buendia, E. Navarro, C. Avendaño, J. Egea and M.G. López: Microglial HO-1 induction by curcumin provides 
antioxidant, antineuroinflammatory, and glioprotective effects. Molec. Nutr. Food Res., 59, 1690-700 (2015).

Philippe, G. and P.J. Landrigan: Neurobehavioural effects of developmental toxicity. Lancet Neurol., 13, 330-338 (2014).

Radha, G., B. Nagendra and S. Yashoda: Study of fluoride content in groundwater of Nawa Tehsil in Nagaur, Rajasthan. J. Environ. Biol., 32, 85-89 (2011).

Randall, L.O. and J.J. Selitto: A method for measurement of analgesic activity on inflammed tissue. Arch. Int. Pharmacodyn. Ther., 111, 409-419 (1957).

Rayavara, K., Kempaiah and K. Srinivasan: Beneficial influence of dietary curcumin, capsaicin and garlic on erythrocyte integrity in high-fat fed rats. J. Nutriti. Biochem., 17, 471-478 (2006).

Suresh, R.N., V.N. Thakare and S.R. Patil: Protective effect of curcumin on experimentally induced inflammation, hepatotoxicity and cardiotoxicity in rats, evidence of its antioxidant property. Exper. Toxicol. Pathol., 63, 419-431 (2011).

Taussky, H.H. and E. Shorr: A micro colorimetric method for the determination of inorganic phosphorus. J. Biol. Chem., 202, 675685 (1953).

Vani, M.L. and K.P. Reddy: Effects of fluoride accumulation on some enzymes of brain and gastrocnemius muscles of mice. Fluoride, $33,17-26(2000)$.

Varner, J.A., K.F. Jensen, W. Horvath and R.C. Isaacson: Chronic administration of aluminium fluoride (or) $\mathrm{NaF}$ to rats in drinking water: Alternations in neuronal and cerebrovascular integrity. Brain Res., 784, 284-98 (1998).

Xiang, Q., Y. Liang, L. Chen, C. Wang, B. Chen and X. Chen: Effect of fluoride in drinking water on children's intelligence. Fluoride, 36, 84-94 (2003). 